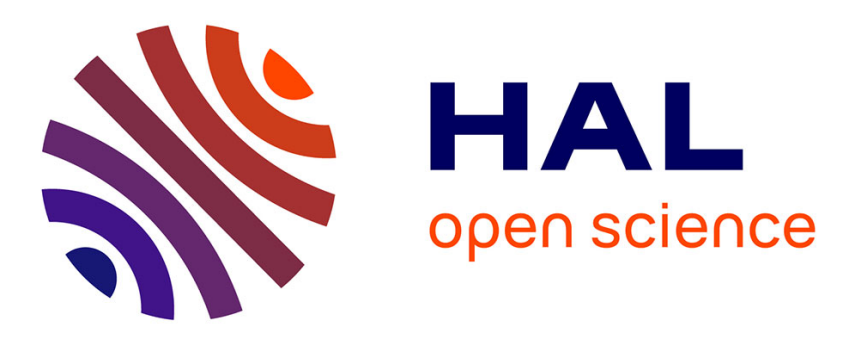

\title{
Pressure induced lattice instability and phase separation in the cuprates
}

\author{
E. Liarokapis, D. Lampakis, E. Siranidi, M. Calaniotou
}

\section{To cite this version:}

E. Liarokapis, D. Lampakis, E. Siranidi, M. Calaniotou. Pressure induced lattice instability and phase separation in the cuprates. Journal of Physics and Chemistry of Solids, 2010, 71 (8), pp.1084. 10.1016/j.jpcs.2010.03.011 . hal-00661914

\section{HAL Id: hal-00661914 https://hal.science/hal-00661914}

Submitted on 21 Jan 2012

HAL is a multi-disciplinary open access archive for the deposit and dissemination of scientific research documents, whether they are published or not. The documents may come from teaching and research institutions in France or abroad, or from public or private research centers.
L'archive ouverte pluridisciplinaire $\mathbf{H A L}$, est destinée au dépôt et à la diffusion de documents scientifiques de niveau recherche, publiés ou non, émanant des établissements d'enseignement et de recherche français ou étrangers, des laboratoires publics ou privés. 


\section{Author's Accepted Manuscript}

Pressure induced lattice instability and phase separation in the cuprates

E. Liarokapis, D. Lampakis, E. Siranidi, M. Calaniotou

PII:

DOI:

Reference:

S0022-3697(10)00057-0

doi:10.1016/j.jpcs.2010.03.011

PCS 6120

To appear in: $\quad$ Journal of Physics and

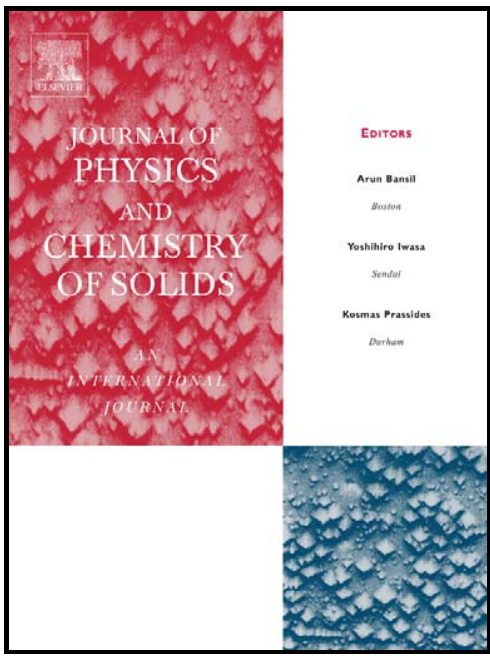

www.elsevier.com/locate/jpcs Chemistry of Solids

Cite this article as: E. Liarokapis, D. Lampakis, E. Siranidi and M. Calaniotou, Pressure induced lattice instability and phase separation in the cuprates, Journal of Physics and Chemistry of Solids, doi:10.1016/j.jpcs.2010.03.011

This is a PDF file of an unedited manuscript that has been accepted for publication. As a service to our customers we are providing this early version of the manuscript. The manuscript will undergo copyediting, typesetting, and review of the resulting galley proof before it is published in its final citable form. Please note that during the production process errors may be discovered which could affect the content, and all legal disclaimers that apply to the journal pertain. 


\title{
Pressure induced lattice instability and phase separation in the cuprates
}

\author{
E. Liarokapis ${ }^{1}$, D. Lampakis ${ }^{1}$, E. Siranidi ${ }^{1}$, and M. Calaniotou ${ }^{2}$ \\ ${ }^{1}$ Department of Physics, National Technical Univ. of Athens, Athens 15780, Greece \\ ${ }^{2}$ Solid State Physics Dept., School of Physics, Univ. of Athens, Athens 15784, Greece
}

\begin{abstract}
High pressure structural studies using a synchrotron source and Raman measurements on various cuprates reveal several structural modifications. The data have shown strong deviations from the normal equation of state at characteristic pressures, hysteresis, and the appearance of additional peaks that can be attributed to a new phase. The combined data of synchrotron angle-dispersive experiments with the optical measurements indicate that at some critical pressures, at least for certain compounds, non-linear effects are observed together with phase separation that affect the distribution of the carriers and the transition temperature. The comparison of the data with those induced by an internal pressure by an atomic substitution indicates that the effect is related to the existence of carriers within the $\mathrm{CuO}_{2}$ superconducting planes.
\end{abstract}

\section{INTRODUCTION}

Chemical doping induces radical modifications in the characteristic properties of the high $T_{c}$ cuprates, with the appearance of superconductivity in a small range of carrier concentration $[1,2]$. The systematic studies over the years have proved that there are several competing order parameters, which complicate the phase diagram [3]. Hydrostatic pressure is one, rather clean, way to investigate the phase diagram and the competing parameters without the complications that arise from possible inhomogeneities in the case of chemical doping. The pressure dependence $\left(\mathrm{dT}_{\mathrm{c}} / \mathrm{dP}^{\mathrm{d}}\right)$ of the superconducting transition temperature $T_{c}$ of the cuprates varies with doping and among the compounds [4]. In some cases a strong pressure increase of $T_{c}$ leads to the discovery of new compounds with higher $T_{c}$ by mimicking the external by an internal (chemical) pressure [5]. Over the last years we have carried out systematic Raman measurements under high pressure on several high $T_{c}$ cuprates, which have indicated lattice instabilities and phase separation at critical pressures, where the transition temperature shows a non-linear dependence on pressure [6-8]. Those studies indicate that the hydrostatic pressure has a non-linear effect on the structure of those compounds and induces lattice distortions and instabilities exactly where $\mathrm{dT}_{\mathrm{d}} / \mathrm{dP}$ shows anomalies [9]. The analysis of the Raman spectral modifications under pressure points to variations in the bond lengths within the $\mathrm{CuO}_{2}$ planes and in the tilting of the $\mathrm{CuO}_{5}$ pyramids [7]. Due to the strong anisotropicity of those compounds, the $\mathrm{dT}_{\mathrm{c}} / \mathrm{dp}$ value actually reflects the average strain dependence of the three lattice axis.

By combining the high pressure Raman data with synchrotron measurements under pressure, we find clear evidence that for certain cuprates $\left(\mathrm{YBa}_{2} \mathrm{Cu}_{3} \mathrm{O}_{7}\right.$ [10], $\mathrm{PrBa}_{2} \mathrm{Cu}_{3} \mathrm{O}_{7}, \mathrm{YBa}_{2} \mathrm{Cu}_{4} \mathrm{O}_{8}$ [11]) there are pronounced deviations from the normal equation of state at pressures, where there is a change in $\mathrm{T}_{\mathrm{c}}$. The comparison of these results with those from rare earth substitutions that induce an internal pressure reveals systematic instabilities in all cuprates studied. In this work, data from several 
hydrostatic pressure measurements are presented and discussed that show the contribution of the lattice to the $\mathrm{dT}_{\mathrm{c}} / \mathrm{dp}$ dependence.

\section{EXPERIMENTAL METHOD}

The Raman measurements have been carried out on several cuprates at high hydrostatic pressures (up to $8 \mathrm{GPa}$ ) using a T64000 Jobin-Yvon triple spectrometer. A liquid nitrogen cooled charge coupled device (CCD) was the detector and the spectrometer was equipped with a microscope of magnification $\times 100(\times 40$ for the hydrostatic pressure measurements). For the high-pressure measurements a MerrillBassett type diamond anvil cell (DAC) was used with a mixture of methanol-ethanol as the pressure-transmitting medium. Various silicon crystals were used inside the gasket to monitor the pressure and any deviation from quasi-hydrostatic conditions. The beam from several lines of an $\mathrm{Ar}^{+}$laser was focused on the sample at a spot of diameter $1-2 \mu \mathrm{m}(\times 100)$ or $3-5 \mu \mathrm{m}(\times 40)$, while the power level was kept below 0.20 $\mathrm{mW}$ (or $0.40 \mathrm{~mW}$ for the high pressure measurements). Always freshly cut samples were used for the study of the various scattering geometries.

The synchrotron xrd measurements were carried out in ESRF with a dense sampling over an extended pressure range (a $\sim 0.5 \mathrm{GPa}$ step up to $\sim 14 \mathrm{GPa}$ in compression). The data have been collected both on pressure increase and on decompression using a DAC and a 4:1 methanol-ethanol mixture as a pressure medium. 2D diffraction images have been recorded with a wavelength $\lambda=0.7117 \AA$ using a MAR345 image plate detector and have been converted to $2 \theta$ patterns after correcting for distortions and refining the detector distance using $\mathrm{a} \mathrm{LaB}_{6}$ standard by fit- $2 \mathrm{~d}[12]$. The intensity vs. $2 \theta$ patterns have been analysed with the Rietveld method using Fullprof [13].

\section{RESULTS AND DISCUSSION}

Figure 1 presents Raman spectra in the zz-scattering polarization of $\mathrm{YBa}_{2} \mathrm{Cu}_{3} \mathrm{O}_{\mathrm{x}}$ for selected hydrostatic pressures and two oxygen concentrations, optimally doped (ortho-I phase with $\left.\mathrm{T}_{\mathrm{c}}=92 \mathrm{~K}\right)$ and half doping $(\mathrm{x}=6.5$, ortho-II phase with $\left.\mathrm{T}_{\mathrm{c}}=60 \mathrm{~K}\right)$. For both concentrations there is an apparent splitting of the in-phase mode of the plane oxygen atoms $\mathrm{O} 2,3$ around $\mathrm{p} \sim 2 \mathrm{GPa}$ marked in figure with straight lines. A similar splitting of this mode has been observed in the $\mathrm{YBa}_{2} \mathrm{Cu}_{4} \mathrm{O}_{8}$ superconductor with the intensity of the two peaks depending on the direction of polarization of the incoming and scattered light [6]. In $\mathrm{Bi}_{2} \mathrm{Sr}_{2} \mathrm{CaCu}_{2} \mathrm{O}_{8}$ the relative mode has also shown a splitting at a similar critical pressure [14] and the effect seems to be characteristic in all cuprates.

Furthermore, pressure induces a non-linear dependence of the frequency of the $\mathrm{A}_{\mathrm{g}}$-phonons in $\mathrm{YBa}_{2} \mathrm{Cu}_{3} \mathrm{O}_{\mathrm{x}}[7,8], \mathrm{YBa}_{2} \mathrm{Cu}_{4} \mathrm{O}_{8}$ [6], and $\mathrm{Bi}_{2} \mathrm{Sr}_{2} \mathrm{CaCu}_{2} \mathrm{O}_{8}$ [14]. Besides in Fig. 1 there is a pronounced broadening for the phonon of the plane copper atoms $(\mathrm{Cu} 2)$, which originally becomes much wider with hydrostatic pressure, but around $\mathrm{p} \sim 3 \mathrm{GPa}$ its width decreases again to practically the same value as at ambient pressure. Similar anomalies in the width appear for the other $\mathrm{A}_{\mathrm{g}}$-symmetry phonons [6]. On the other hand, the $\mathrm{B}_{1 \mathrm{~g}}$-symmetry phonon, which appears in the Raman spectra in xx-polarization does not have any pressure dependence anomaly. This happens for both oxygen concentrations of the superconducting $\mathrm{YBa}_{2} \mathrm{Cu}_{3} \mathrm{O}_{\mathrm{x}}$ and for $\mathrm{YBa}_{2} \mathrm{Cu}_{4} \mathrm{O}_{8}$ [6-8] but it does not appear in the non-superconducting $\mathrm{PrBa}_{2} \mathrm{Cu}_{3} \mathrm{O}_{7}$ compound (Fig.2). The xx-polarization spectra of $\mathrm{PrBa}_{2} \mathrm{Cu}_{3} \mathrm{O}_{7}$ are not pressure 
dependent (Fig.2), similar with the corresponding spectra in the xx-polarization of the superconducting compounds $\mathrm{YBa}_{2} \mathrm{Cu}_{3} \mathrm{O}_{\mathrm{x}}$ (ortho-I and ortho-II phases).

The observed hydrostatic pressure induced Raman spectral modifications bears resemblance with the pressure dependence of the superconducting transition temperature of these compounds $[5,8]$. Therefore, they may be related with charge transfer from the chains to planes, its redistribution between the $\mathrm{CuO}_{2}$ planes, and other effects. To this context subtle structural modifications and lattice distortions should correlate with pressure modifications of $\mathrm{T}_{\mathrm{c}}$ and their study can contribute to the efforts of understanding the mechanisms underlying superconductivity in the high temperature superconducting cuprates.

Structural studies under hydrostatic pressure previously reported in these compounds were limited either to the low pressure range (up to $0.6 \mathrm{GPa}$ ) [15] or by the low resolution of the energy dispersive diffraction method, which were used for the experiment [16]. Structural studies of the $\mathrm{YBa}_{2} \mathrm{Cu}_{4} \mathrm{O}_{8}$ compound as a function of pressure gave only marginal evidence that the changes of the lattice parameters and bond lenghts follow the non-linear pressure dependence observed for $T_{c}$ above $4 \mathrm{GPa}$ $[17,18]$.

We have measured high quality fully refinable angular-dispersive synchrotron powder diffraction patterns under high hydrostatic pressure (up to $\sim 14 \mathrm{GPa}$ with a $\sim 0.5 \mathrm{GPa}$ step) of various high $\mathrm{T}_{\mathrm{c}}$ superconducting cuprates, e.g. the $\mathrm{YBa}_{2} \mathrm{Cu}_{4} \mathrm{O}_{8}$, which is a model compound for the under-doped oxides, the optimally doped $\mathrm{YBa}_{2} \mathrm{Cu}_{3} \mathrm{O}_{\mathrm{y}}$ superconductor, and the non-superconducting $\mathrm{PrBa}_{2} \mathrm{Cu}_{3} \mathrm{O}_{7}$ cuprate. Our measurements of high quality synchrotron powder diffraction patterns with a dense sampling over an extended pressure range document a clear deviation of the structural parameters from the expected equation of state correlating with phase separation effects.

With the application of hydrostatic pressure, the $\mathrm{YBa}_{2} \mathrm{Cu}_{3} \mathrm{O}_{7}$ superconductor shows a strong anomaly mainly on the c-axis and to a smaller extend on the b-axis [10]. The data are presented in Fig. 3 both for increasing and decreasing pressures. It is clear that there is a deviation from expected pressure dependence in the pressure range 3.5-10.5 GPa. Besides, there is an obvious irreversibility on the pressure dependence, and the data at reducing pressure follow the anticipated normal equation of state, without any anomaly. At the pressure $\sim 3.5 \mathrm{GPa}$ where the data start to deviate from the normal behaviour, new peaks appear in the xrd patterns. The whole structure including the new peaks could not be fitted assuming the formation of a single homogeneous superstructure phase. Therefore, it is induced that the new peaks should correspond to another phase. This phase disappears together with the new peaks upon pressure release at $\sim 3.0 \mathrm{GPa}$ [10], to reappear again if pressure is increased above the same level [11]. If somebody tries to index the new peaks independently of the main phase, it turns out that it could be indexed as a superstructure with about the same c-axis and double the a- and b-axis.

In Fig.3 the pressure dependence of the c-axis is compared with the modifications recorded in the Raman spectra for the phonon of the apical oxygen atom (frequency and width). Similar behaviour has been observed for the other $\mathrm{Ag}_{\mathrm{g}}$ symmetry phonons of the two superconducting phases of $\mathrm{YBa}_{2} \mathrm{Cu}_{3} \mathrm{O}_{\mathrm{x}}$ [7]. It is seen that up to $\sim 2 \mathrm{GPa}$ there is a continuous increase in the apex phonon frequency, which subsequently remains constant in the interval $\sim 2-3.5 \mathrm{GPa}$, to increase again at higher pressures. The width of the $\mathrm{A}_{\mathrm{g}}$-symmetry phonons shows also unconventional pressure dependence. It increases up to $\sim 2 \mathrm{GPa}$ and subsequently decreases at higher pressures reaching a minimum value of the same amount as in the ambient pressure 
around $3.5 \mathrm{GPa}$, i.e. at the pressure where the new peaks appear in the xrd patterns and a deviation of the c-axis from the normal equation of state. This unconventional pressure dependence of the phonon modes indicates a phase transformation at this pressure range with a new phase appearing in the same pressure range. The fact that the same phonon modes are present in all spectra proves that there is no structural phase transition to another crystal symmetry, but rather small lattice distortions and sudden modifications in certain bond lengths at a critical hydrostatic pressure.

Looking closely at the variation of the bond lengths with pressure, one finds that mainly the bond distances of the $\mathrm{Cu} 2$ atom with the oxygen atoms in the planes and the apical are affected [10]. Actually, there is a deviation from the normal reduction of these bond lengths around $3.5 \mathrm{GPa}$, which explains the modifications in the lattice constants at the same pressure. Since the apical oxygen controls the transfer of carriers to the $\mathrm{CuO}_{2}$ planes [19], the bond length variations reflect changes in the charge transfer to the superconducting planes from the $\mathrm{CuO}$ chains.

In principle, one could mimic the external hydrostatic pressure with rare earth substitutions of varying ionic radius [20,21]. Therefore, if the observed effects under hydrostatic pressure are strictly related to the strain, one should expect to observe similar modifications in the lattice constants and the bond lengths by combinations of rare earth substitutions [20,21].

Figure 4 presents data from various rare earth combinations; $\mathrm{RBa}_{2} \mathrm{Cu}_{3} \mathrm{O}_{7}$ (R123, filled black squares), $\mathrm{La}_{0.5} \mathrm{R}_{0.5} \mathrm{Ba}_{2} \mathrm{Cu}_{3} \mathrm{O}_{7}$ (La-R123, open blue squares), $\mathrm{Pr}_{0.5} \mathrm{R}_{0.5} \mathrm{Ba}_{2} \mathrm{Cu}_{3} \mathrm{O}_{7}$ (Pr-R123, open green triangles), and $\mathrm{Y}_{1-\mathrm{x}} \mathrm{Pr}_{\mathrm{x}} \mathrm{Ba}_{2} \mathrm{Cu}_{3} \mathrm{O}_{7}$ (Y-Pr123, filled red circles). The variation of the bond lengths $\mathrm{Cu} 2-\mathrm{O} 1$ (apical), $\mathrm{Cu} 2-\mathrm{O} 3$, and the c-axis with the average ionic radius are presented. For an average radius of $\sim 1.08 \AA$, there is a deviation in the c-axis mainly for the La-R123 compounds. The compounds with Pr seem to have zero or very small anomalies. The same happens for the bond lengths; the anomaly involves the La compounds, and it is smaller or absent in the Pr substitutions. Only the $\mathrm{Cu} 2-\mathrm{O} 1$ distance varies practically the same way in all substitutions, defining again a critical average ionic radius, where there is a modification in the charge transfer to the $\mathrm{CuO}_{2}$ planes from the chains.

The large variations in the data points can be understood, because in most of the cases the amount of oxygen was not measured and therefore the exact doping due to oxygen may vary among the compounds. But, the decrease of the $\mathrm{Cu} 2-\mathrm{O} 1$ distance is consistent with an increase in the amount of charge transfer to the superconducting planes, and it does not agree with the disappearance of superconductivity in most of the compounds at large ionic radii. For example the Y-Pr123 and the Pr-R123 compounds are non-superconducting towards the large ionic radii, i.e., exactly after the critical radius of $\sim 1.08 \AA$. So, the structural data start to deviate very close to the interatomic distances where, for some reason, the carrier properties of the compounds are modified. On the other hand, the La-R123 system remains superconducting in the whole range of ionic radii, in spite the fact that it also shows deviations for the $\mathrm{Cu} 2$ $\mathrm{O} 1$ bond length at the same critical ionic radius (Fig.4, middle). The main difference of the La compounds from the other non-superconducting compounds is the increase of the $\mathrm{Cu} 2-\mathrm{O} 3$ distance at the same average radius (Fig.4, top), which is related with the redistribution of the carriers among the $\mathrm{Cu} 2$ and $\mathrm{O} 2,3$ atoms. It should be noted that in the mixed compounds, one may have phase separation, especially when there is a large difference between the ionic radii of the two rare earths or yttrium (for average ionic radii smaller than $1.08 \AA$, Ref.[21]). The superconductivity in those systems may be a result of percolation in the phase separated system, where one should expect $\mathrm{RBa}_{2} \mathrm{Cu}_{3} \mathrm{O}_{\mathrm{x}}$ nano-sized regions rich in each rare earth or yttrium [20,21]. This 
complicates the interrelation of the structural and Raman data with the variation of $\mathrm{T}_{\mathrm{c}}$. Towards the large values of the ionic radius, one expects the system to behave as homogeneous and therefore, we should look at this region to identify modifications in $\mathrm{T}_{\mathrm{c}}$ and the structural data. The basic difference is between the La-R123 and the other non-superconducting compounds, which may indicate the importance of the bond length distance within the superconducting planes. Therefore, the strain itself is not the only parameter that defines the effect of pressure, internal or external to the compound, but there are other factors involved that are related to the carriers and the phase separation that affect the superconducting properties of the cuprates. One should always have in mind the lattice effects as well, that can mask the $\mathrm{dT}_{\mathrm{c}} / \mathrm{dp}$ dependence in the cuprates.

\section{CONCLUSIONS}

We have carried out a systematic comparison of the hydrostatic pressure dependence of the structural and Raman data for several cuprates. It appears that the synchrotron structural data fully support the original findings of the Raman spectra under pressure bringing more information on the changes in the bond lengths, which are responsible for the spectral modifications. The study of the non-superconducting $\mathrm{PrBa}_{2} \mathrm{Cu}_{3} \mathrm{O}_{7}$ compound shows that there is no structural anomaly, both in the xrd data and the Raman spectra, pointing to some connection of these changes with the amount and the distribution of the carriers. The comparison with all published data on the rare earth substitutions for yttrium that induce an internal pressure, supports our findings and proves that the effect is not simply related to the amount of internal strain, but it is also interrelated to the amount and distribution of carriers, explaining the correlation of the structural anomalies with the $\mathrm{dT}_{\mathrm{c}} / \mathrm{dp}$ non-linear dependence.

\section{ACKNOWLWDGEMENTS}

Work partially supported by the E.C. STREP Project COMEPHS.

\section{REFERENCES}

[1] A. Gantis, M. Calamiotou, D. Palles, D. Lampakis, and E. Liarokapis, Phys. Rev. B 68, 064502 (2003).

[2] M. Calamiotou, A. Gantis, I. Margiolaki, D. Palles, E. Siranidi, and E. Liarokapis, J. Phys.: Condens. Matter 20, 395224 (2008).

[3] S. Sachdev, Science 288, 475 (2000).

[4] N. Mori, C. Murayaha, H. Takahashi, H.Kaneko, K. Kawabata, Y. Iye, S. Uchida, H. Takagi, Y. Tokura, Y.Kubo, H.Sasakura, and K.Yamaya, Physica C 185-189, 40 (1991).

[5] J. Schilling, J. Phys. Chem. Solids 59, 553 (1998).

[6] E. Liarokapis, D. Lampakis, T. Nishizaki, and C. Panagopoulos, High Pressure Research 18, 109 (2000).

[7] D. Lampakis, D. Palles, E. Liarokapis, S. M. Kazakov, and J. Karpinski, Phys. Rev. B 72, 014539(2005)

[8] D. Lampakis, E. Liarokapis, J. Karpinski, C. Panagopoulos, and T. Nishizaki, Journal of Superconductivity: Incorporating Novel Magnetism, 17, 121 (2004). 
[9]-U. Koch, N. Lotter, J. Wittig, W. Assmus, B. Gegenheimer, and K. Winzer, Sol. State Comm. 67, 959 (1988).

[10] M. Calamiotou, A. Gantis, D. Lampakis, E.Siranidi, E. Liarokapis, I. Margiolaki, and K. Conder, EPL 85, 26004 (2009).

[11] M. Calamiotou, A. Gantis, E. Siranidi, D. Lampakis, K. Conder, and E. Liarokapis, to be published.

[12] A. P. Hammersley, S.O. Svensson, M. Hanfland, A. N. Fitch, and D. Hausermann, High Press. Res., 14, 235, (1996).

[13] J. Rodriguez-Carvajal, Physica B, 192 (1993) 55.

[14] E. Liarokapis, D. Lampakis, C. Panagopoulos, and T. Nishizaki, High Pressure Research 23, 111 (2003).

[15] J. D. Jorgensen, P. Shiyou, P. Lightfoot, D. G. Hinks, B. W. Veal, B. Dabrowski, A. P. Paulikas, R. Kleb, and I. D. Brown, Physica C171, 93 (1990), H. Takahasi, H. Shaked, B. A. Hunter, P.G. Radaelli, R. L. Hitterman, D. G. Hinks, and J. D. Jorgensen, Phys. Rev. B 50, 3221, (1994).

[16] M. J. Akhtar, Z. N. Akhtar, and C. R. A. Catlow, J. Phys.: Condens Matter, 2, 3231 (1990)

[17] R.J. Nelmes, J.S. Loveday, E. Kaldis, and J. Karpinski, Physica C 172, 311 (1990).

[18] D.R. Allan, and R.J. Nelmes, Physica C 235-240, 863 (1994).

[19] R.J. Cava, A.W. Hewat, E.A. Hewat, B. Batlogg, M. Marezio, K.M. Rabe, J.J. Krajewski, W. F. Peck, Jr., L.W. Rupp, Jr, Physica C165 419 (1990).

[20] M. Calamiotou, A. Gantis, D. Palles, D. Lampakis, E. Liarokapis, and A. Koufoudakis, Phys. Rev. B 58, 15238 (1998).

[21] G. D. Chryssikos, E. I. Kamitsos, J. A. Kapoutsis, A. P. Patsis, V. Psycharis, A. Koufoudakis, Ch. Mitros, G. Kallias, E. Gamari-Seale, and D. Niarchos, Physica C 254, 44 (1995). 


\section{FIGURE CAPTIONS}

Figure 1. Characteristic Raman spectra under hydrostatic pressure of the $\mathrm{YBa}_{2} \mathrm{Cu}_{3} \mathrm{O}_{\mathrm{x}}$ superconductor for two oxygen doping levels with $\mathrm{T}_{\mathrm{c}} 92 \mathrm{~K}$ (ortho-I) and $60 \mathrm{~K}$ (orth-II phase). The modifications in the $\mathrm{Cu} 2$ phonon are marked together with the appearance of another peak of the in-phase oxygen mode (straight lines).

Figure 2. Raman spectra under hydrostatic pressure of the $\operatorname{PrBa}_{2} \mathrm{Cu}_{3} \mathrm{O}_{7}$ compound, which is not superconducting, in the two scattering polarizations ( $\mathrm{xx}$ and $\mathrm{zz}$ ). In the $\mathrm{xx}$-polarization the $\mathrm{B}_{1 \mathrm{~g}}$-phonon is marked and in the other the $\mathrm{Cu} 2$ phonon, both unmodified by the pressure.

Figure 3. The comparison of the apical phonon frequency and width (upper part) with the pressure dependence of the c-axis (lower part) in the $\mathrm{YBa}_{2} \mathrm{Cu}_{3} \mathrm{O}_{7}$ superconductor. Crosses define the decompression data and full squares those at increasing pressure.

Figure 4. The variation of the $\mathrm{Cu} 2-\mathrm{O} 3$ (top), $\mathrm{Cu} 2-\mathrm{O} 1$ (middle) bond lengths and the $\mathrm{c}-$ axis (bottom) vs. the average ionic radius for various compounds of the yttrium family: $\mathrm{RBa}_{2} \mathrm{Cu}_{3} \mathrm{O}_{7}$ (R123), $\mathrm{La}_{0.5} \mathrm{R}_{0.5} \mathrm{Ba}_{2} \mathrm{Cu}_{3} \mathrm{O}_{7}$ (La-R123), $\mathrm{Pr}_{0.5} \mathrm{R}_{0.5} \mathrm{Ba}_{2} \mathrm{Cu}_{3} \mathrm{O}_{7}$ (Pr$\mathrm{R} 123)$, and $\mathrm{Y}_{1-\mathrm{x}} \mathrm{Pr}_{\mathrm{x}} \mathrm{Ba}_{2} \mathrm{Cu}_{3} \mathrm{O}_{7}$ (Y-Pr123), where $\mathrm{R}$ defines a rare earth ion or yttrium. 


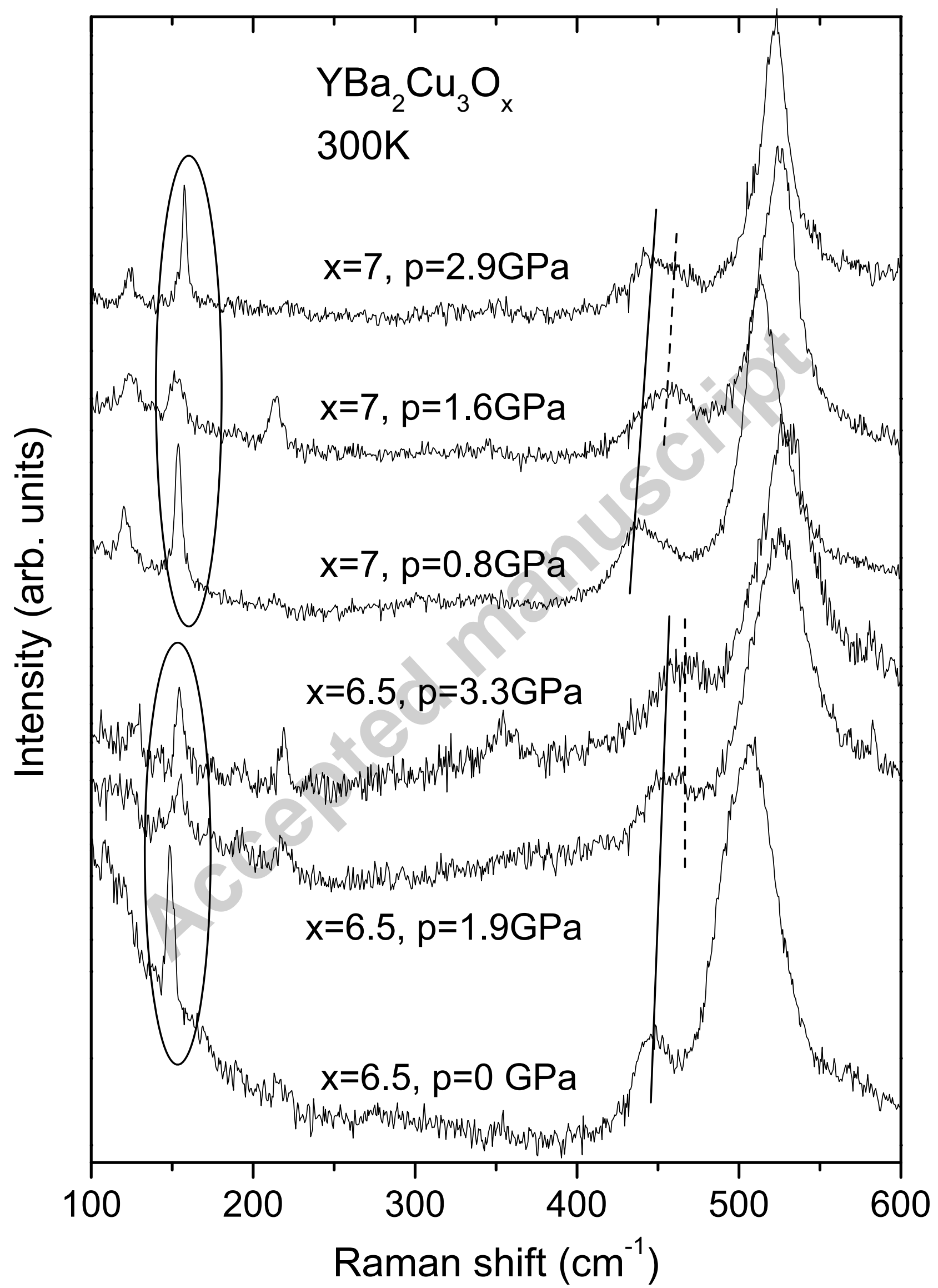




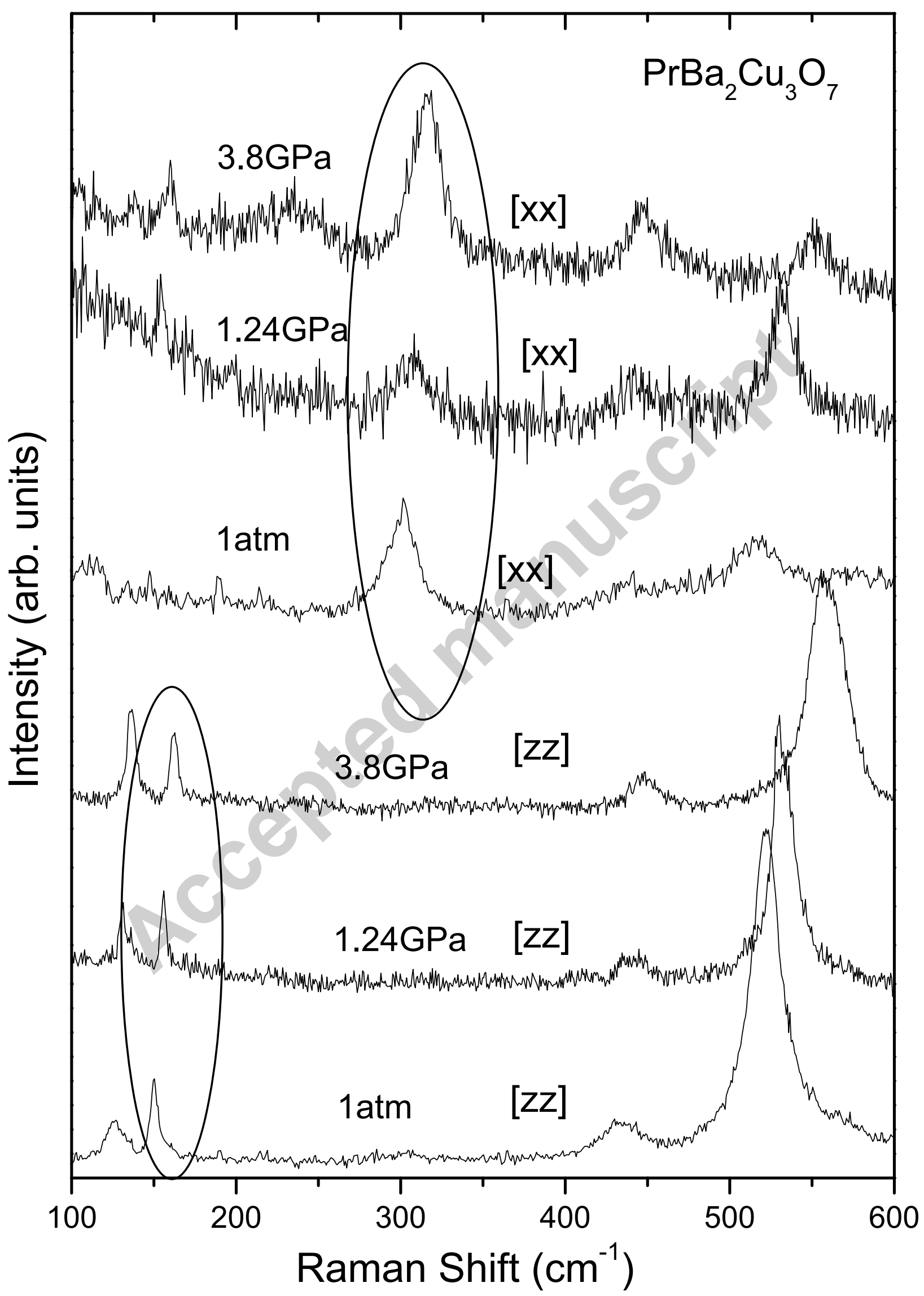




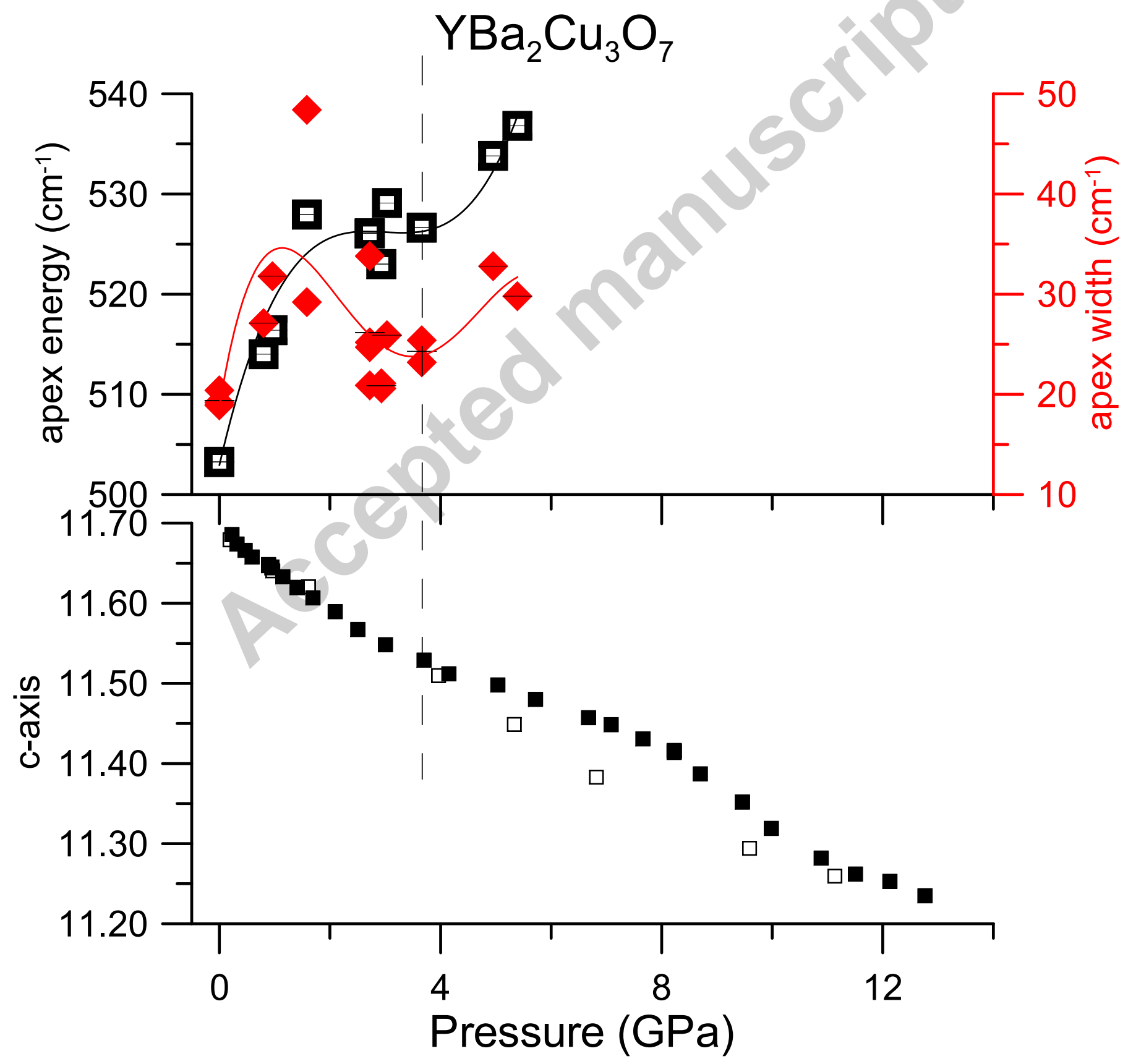



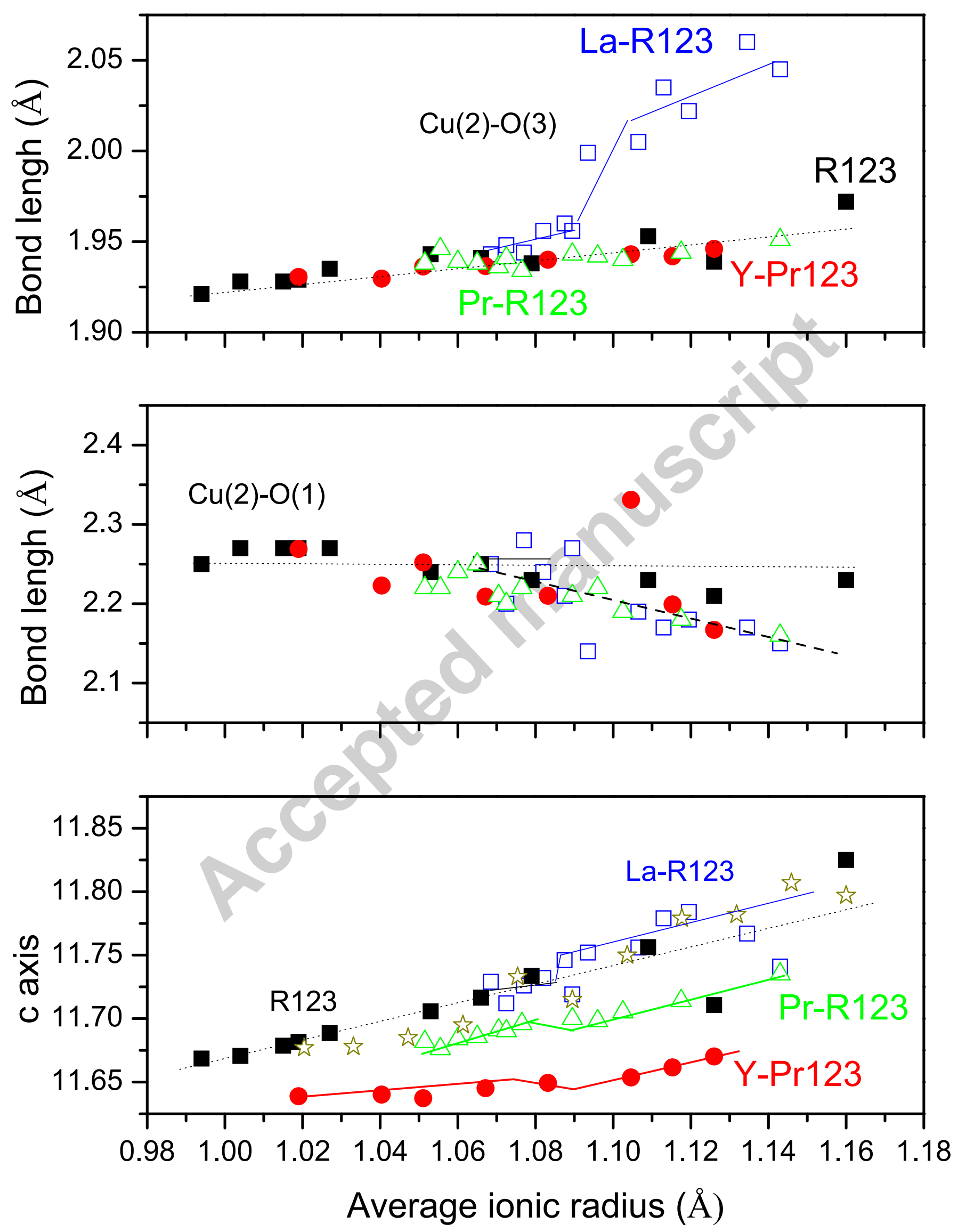